\title{
Body Packing - The way to obscure illicit drugs
}

Gaurav Patel, MD, Hemantkumar Raval, MD, and Bhargav Patel, MD

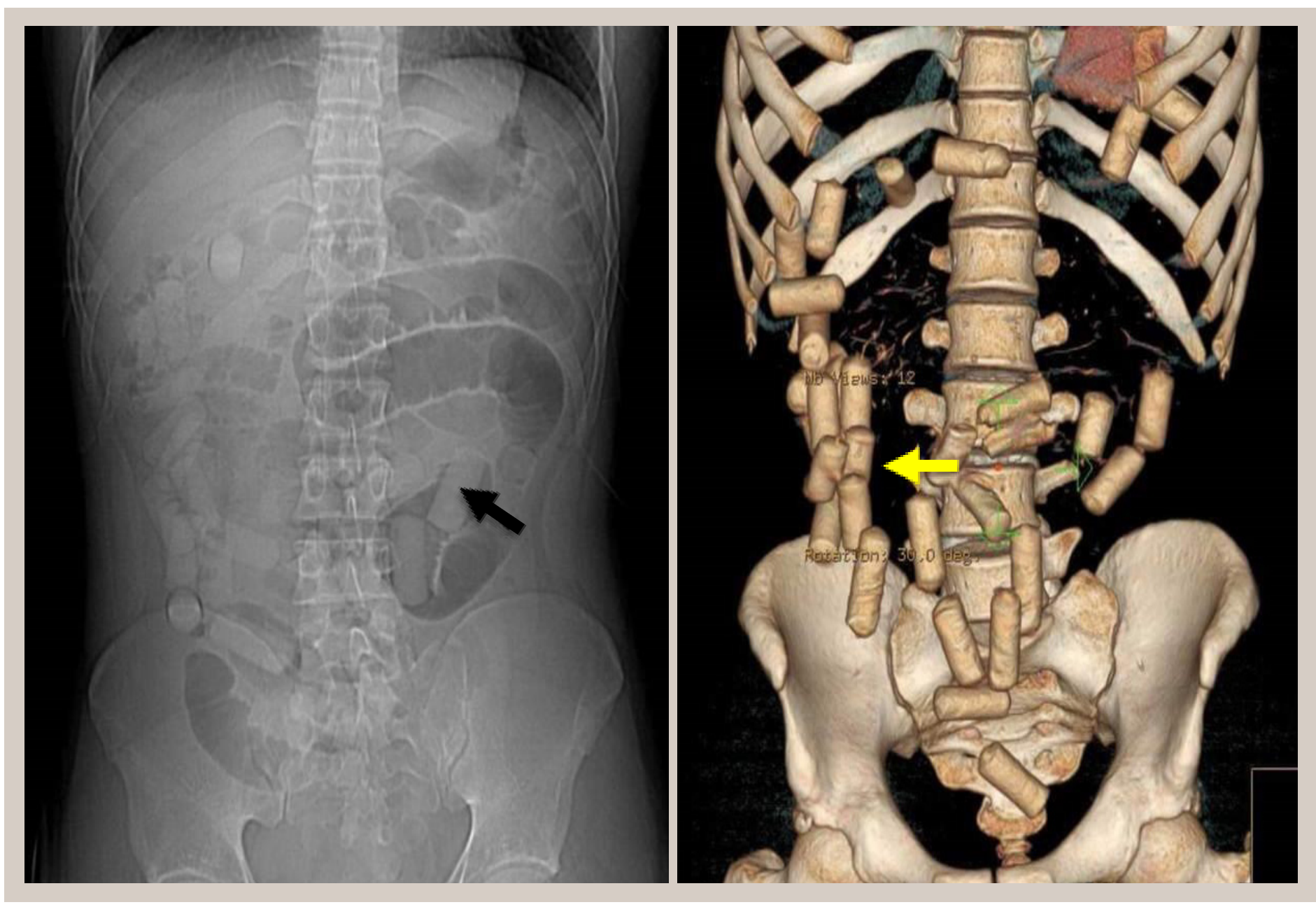

Figure 1 A KUB showed multiple foreign bodies in the area of distal small bowel and colon (Black Arrow) and 3D reconstructed image showed Drug filled Pallets (Yellow Arrow).

\section{INTRODUCTION}

Body packing is a common method for drug smuggling across international borders, since hiding drug packages in body cavities is difficult to detect. This situ

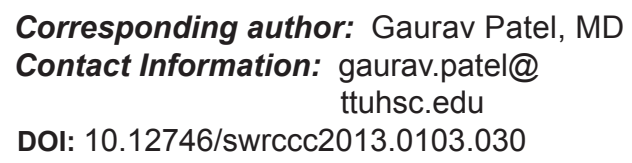

-ation can create medical and surgical complications ranging from intoxication to intestinal obstruction. Here we present a case of body packing in a 20 -year-old man.

\section{Case Presentation}

A 20-year-old Hispanic man was brought in by federal agents from a nearby airport complaining of "abdominal discomfort". Physical examination revealed normal sized, reactive pupils and a soft, non-tender abdomen with hypoactive bowel sounds. Laboratory 
tests were unremarkable. A KUB revealed multiple foreign bodies in the distal small bowel and colon which were confirmed with a CT scan of the abdomen with contrast (Panel A, Arrow) and 3D reconstructed image (Panel B, Arrow showing Drug filled Pallets). The foreign bodies were later confirmed to be illicit drugs. The patient was monitored in the critical care unit and was given oral gut lavage; sixty-five drug pallets were successfully retrieved rectally without any complications.

\section{Discussion}

Body packing is practiced for drug smuggling, especially by young men and women. Acute intoxication due to release of cocaine/heroine from ruptured packets can cause life threatening arrhythmias and acute myocardial ischemia. Intestinal obstruction and/or perforation by these packages are not uncommon. Radiographic imaging, including computed tomography scans, will confirm the suspected diagnosis. Asymptomatic patients can be managed with close monitoring in the ICU; treatment is whole bowel irrigation with polyethylene glycol or electrolyte lavage solution. Sometimes this is difficult due to poor patient cooperation. Endoscopic retrieval of drug filled pallets is not safe and potentially harmful because of chances of rupture is high.

\section{Conclusion}

Body packing can create medical and surgical emergencies requiring urgent intervention to reverse life threatening situations.

\footnotetext{
Author Affiliation: Dr G Patel is a Fellow in Pulmonary/Critical Care Medicine at Texas Tech University Health Science Center, Lubbock, TX, Dr Raval is a Fellow in Pulmonary Medicine at Jamaica Hospital Medical Center, Richmond Hill, NY, and Dr B Patel is an Internal Medicine Resident at Jamaica Hospital Medical Center, Richmond Hill, NY. Received: $4 / 26 / 13$

Accepted: 4/30/13

Published online: $7 / 16 / 13$

Reviewers: Richard Winn MD, Raed Alalawi MD

Conflict of Interest Disclosures: None
}

\section{References}

1. Deitel M, Syed AK. Intestinal obstruction by an unusual foreign body. Can Med Assoc J 1973; 109:211.

2. Hutchins KD, Pierre-Louis PJ, Zaretski L, et al. Heroin body packing: three fatal cases of intestinal perforation. J Forensic Sci 2000; 45:42

3. Pidoto RR, Agliata AM, Bertoline R, Mainini A, Rossi G, Giani G. A new method of packaging cocaine for international traffic and implications for the management of cocaine body packers. J Emerg Med 2002:23:149-53.

4. Silverberg D, Menes T, Kim U. Surgery for "Body Packers": A 15 year experience. World J Surg 2006: 30:541-6. 